\title{
Quantitative Analysis on the Relationship between Hubei's Financial Input in Education and the Economic Growth
}

\author{
Jianguo $\mathrm{WANG}^{1 \dagger}$, Xiaoyan Wang ${ }^{1 \dagger}$, Jue $\mathrm{Fu}^{1}$, Changjun Zhang ${ }^{2}$, Jiangqiang \\ WANG $^{3}$, Kai Deng ${ }^{2 *}$
}

1 Center of Health Administration and Development Studies, Hubei University of Medicine, Shiyan, 442000, China

2 Institute of Eugenics and Genetics, Renmin Hospital, Hubei University of Medicine, Shiyan 442000 China

\author{
3 Beijing Sports International Economic Conference Servive Center,Beijing, 100088, China \\ $\dagger$ These authors contributed equally to the work \\ * Corresponding author: Kai Deng; email: dkeanig@163.com
}

Keywords: education investment; economical growth; granger causality; vector autoregression

\begin{abstract}
This essay conducts an empirical research and quantitative analysis with the application of econometric methods and models, such as VAR theory and impulse response function, on the relations between the financial input of Hubei in education and the economic development during the past decade. Studies show that there exists an equilibrium relationship and coordinated interaction between Hubei's financial input on education and its actual economic growth. The fluctuation of educational investment is bound up with that of economic increase with causality. It is feasible and effective to realize rapid growth of economic aggregate through enhancing educational input, and a long-term policy, but not a short-term one, which should be adopted when utilizing educational investment to boost the economy.
\end{abstract}

\section{Introduction}

According to the traditional theory of economic growth, the investment in material capital is playing a main role in promoting the economic development. During 1950s, attention had been paid to the significance of education in the economic growth. Theodore W. Schultz, an American economist made an elaborate explanation and analysis, in his theory of human capital, on the contribution made by education to the economic growth during 1960 AEA Annual Meeting. After that the significance of education investment in economic development has attracted much attention from western economists. The western economists even tried to prove the relationship between education investment and economic growth via the methods of econometric analysis. According to the study made by Schultz, only $20 \%$ of the agricultural production growth was triggered by the material capital accumulation since postwar, while $80 \%$ of it could be attributed by the education development and its related science and technology. For example, the result of the study showed that education make up of $13.7 \%$ of the total contribution to the growth rate of American National Income during 1929- 1985. Some Chinese scholars also conducted empirical research, some of them held that the development of economy resulted in the education progress, and some believed that economic development resulted from the advancing of education, while others contended that there was a cause-and-effect relationships between the two. ${ }^{[1]}$

\section{Data Specification}

Education investment consists of the investment from government, the enterprises and the individuals. In China, the government is generally becoming the main source of education investment and in consideration of the representativeness and the availability of the data, The operating education expenses (EDU) in Hubei Province has been chosen as the variable and the 
GDP of Hubei Province as the indicator for measuring the economic growth. In order to eliminate the influence caused by the inflation the amount of OEE and GDP calculated on the price of the current years will be adjusted through retail price index (RPI). The year of 1979 will be regarded as the base period for RPI. In addition, in order to eliminate the heteroscedasticity, the logarithm transformation will be carried out on the two variables. The actual OEE investment and the GDP investment will be defined as the LEDU and LGDP through natural logarithm. The applied software will be Eview5.1.

\section{Analysis on the co-integration and cause-and-effect relationship between economic growths and education Financial Education Investment}

Professor Engle and Professor Granger proposed the Theory of Co-integration in 1987, which revealed that if the linear combination with non-stationary variable in same order was the stationary series, there would possible be long-term stable equilibrium relationship among these variables, which is called the co-integration relationship. In term of economy, the existence of this co-integration relationship means a change of a variable could be influenced by this or these variables. In order to make analysis on the co-integration relationship between economic growth and financial education investment, to carry out the unit root test on the sequence of variable.

\subsection{Unit Root Test on Sequence of Variables}

In consideration of the potential higher autocorrelation among the sequence, ADF unit root test method to test if there is unit root in the sequence of LGDP, LEDU, first-order difference sequence $-\Delta$ LGDP, $\Delta$ LEDU and second-order difference sequence - $\Delta 2$ LGDP, $\Delta$ 2LEDU. Based on the time-order character of the level sequence and difference sequence, the test equation for level sequence consists of constant term and the trend term of linear time, while the test equation for difference sequence only contains constant item. At the same time, the lag intervals for endogenous of the experimental model was defined according to the SIC standard, the result is showed in Table 1. Table 1. Stationary Test

\begin{tabular}{|l|l|l|l|l|l|}
\hline variables & ADF & Type & $1 \%$ critical value & $5 \%$ critical value & conclusion \\
\hline LGDP & -1.1257 & $(\mathrm{c}, \mathrm{t}, 0)$ & -4.4983 & -3.6584 & nonstationary \\
\hline LEDU & -2.3885 & $(\mathrm{c}, \mathrm{t}, 1)$ & -4.5325 & -3.6736 & nonstationary \\
\hline$\Delta$ LGDP & -2.6840 & $(\mathrm{c}, 0,0)$ & -3.8315 & -3.0299 & nonstationary \\
\hline$\Delta$ LEDU & -3.0317 & $(\mathrm{c}, 0,0)$ & -3.8315 & -3.0299 & nonstationary \\
\hline$\Delta^{2}$ LGDP & -5.4016 & $(\mathrm{c}, 0,0)$ & -2.6997 & -1.9614 & stationary \\
\hline$\Delta^{2}$ LEDU & -4.3502 & $(\mathrm{c}, 0,0)$ & -2.6997 & -1.9614 & stationary \\
\hline
\end{tabular}

$\Phi c$ is constant item, $t$ is trend item, $\mathrm{k}$ is lag Intervals for endogenous

2The standard for selecting $\mathrm{k}$, the lag phase is based on the minimum of the AIC and SC.

The result shows that, when the significance level reaches $1 \%$, LGDP,LEDU, $\triangle$ LGDP、 $\triangle$ LEDU are the non-stationary sequence, while the $\triangle 2 \mathrm{LGDP}$ and $\triangle 2 \mathrm{LEDU}$, the integrated series for second-order are the stationary time series

\subsection{The Test on Co-integration between Economic Growth and Financial Education} Investment

Although LGDP and LEDU are non-stationary, there might be some stable linear combination between them, which reflected the stable and long-term relationship between the variables, which is co-integration relationship. The Maximum Likelihood method and Engle-Granger method which was invented by Johansen $(1988,1992)$ has been adopted to carry out test and estimation on the system. Only in the case of the two time series might there be a linear co-integration relationship between the two. When there is only one co-integration between the two time series, EG method is effective. According to the previous test, we know that LGDP and LEDU belongs to the second-order integrated sequences, which meet the requirement of the co-integration test, therefore, the EG method could be adopted. To estimate the long-term co-integration relationship by least square method, we gen get the result as the followed:

$\mathrm{LGDP}=4.390818+0.899245 \times$ LEDU 


$$
\text { (142.5257) (100.7474) }
$$

\section{$\mathrm{R}^{2}=0.998132 \quad \mathrm{~F}=10150.03$}

Adjusted R-squared $=0.998033$

Among this, the data in the brackets refer to the statistic of $t$, the estimating value. The goodness-of-fit and the amended-goodness-of-fit of the equation are satisfactory, every test parameter is not zero. Statistic $f$ shows that the equation is true. The statistical property of the regression equation is qualified.

If there is co-integration relationship in LGDP and LEDU, the regressed residual sequencest should be stationery. Then after carrying out stationery test on the residual sequence, we could get the following result: the value of ADF is -2.003641 , which is less than -1.959071 , the critical value of notable level of $5 \%$. Hence it is believed that there is no unit root in the residual item. It is a stationery sequence, that is to say there is only-co-integration relation between GDP and financial education investment in Hubei province in the recent 10 years. From the Table we can see that the financial education investment increases by $1 \%$, the GDP will grow by $0.899245 \%$ accordingly.

\section{The Cause-and-Effect Relationship between Economic Growth and Financial Education Investment}

The result of Co-integration test showed that there is a long-term equilibrium relationship between the financial education investment and economic growth, but the co-integration test could not confirm that there is statistical cause-and-effect relationship between the two. It can only inferred there is possible Granger causality between LGDP and LEDU. Whether this Equilibrium relationship can make cause-and-effect relationship; that is whether the increase of financial education investment bring about the economic growth or the economic growth sparked the increase of the financial education investment should be further studied and analyzed.

We carried out the test on the Granger causality between GDP and the financial education investment and got the following result:

Table 2.Granger Causality

\begin{tabular}{|c|c|c|c|}
\hline null hypothesis & observed value & F- statistics & Value of P \\
\hline LGDP is not the reason of LEDU & 16 & 48.3025 & 0.00031 \\
\hline LEDU is not the reason for LGDP & & 7.33308 & 0.02370 \\
\hline
\end{tabular}

From the Table 2 we can see that the probability of GDP not being the reason for the increase of education investment is $0 \%$; in case of $5 \%$, the null hypothesis is rejected, that is to say the increase of GDP will affect the rise of education investment greatly. For another null hypothesis that the education investment is not the reason for the growth of GDP, of which the possibility is $2.37 \%$; and in case of $5 \%$ the null hypothesis is rejected, which means that the education investment is the reason for GDP growth, and the development of education will promote the growth of GDP greatly. Hence, it can be recognized that the significant increase of financial education investment affect the growth of GDP greatly, and vice-verse in Hubei Province, which means there were causal relationships between the two.

\section{VAR Model}

According to the principle of the minimum of AIC and SC, to select the lag order as 2 and under this circumstance, carrying out JB normality test, LM autocorrelation test and White test on Model residuals of VAR (2), it shows that the residuals are in conformity with normal distribution, and they are not auto-correlated and they consist of no heteroscedasticity. In addition all the reciprocals of all the model are less than 1, it means that the structure of VAR(2) is stable and the statistical property of it is good, which could be the base for the subsequent impulse analysis. The estimation result of VAR (2) is shown in Table 3, among which the coefficient of determinations of the two regression functions reach to 0.998608 and 0.998769 respectively, which means the fitting degree of the two regression is good enough. 
Table 3. Estimation of VAR (2) Model

\begin{tabular}{c|c|c}
\hline explaining variable & regression function LGDP & regression function LEDU \\
\hline LGDP (-1) & 1.263895 & 0.185124 \\
LGDP (-2) & 0.490329 & 1.037186 \\
LEDU (-1) & -0.225794 & 0.737664 \\
LEDU (-2) & -0.466796 & -0.847449 \\
C & -3.103170 & -5.129911 \\
R-Squared & 0.998608 & 0.998769
\end{tabular}

The Maximum likelihood function value of VAR(2) $\quad 77.692 \mathrm{AIC}=-7.125452 \quad \mathrm{SC}=-6.628$

\section{Conclusion and Suggestion}

There is coordinative and interactive equilibrium relationship between the education financial education investment and the actual economic growth in Hubei Province, the education investment shared a close relationship with economic growth.

Financial education investment is playing a significant role in economic growth in Hubei province, as well as an important factor to promote the rise of economy. To increase the education investment could contribute to the increase of the real economy; while to decrease the investment on education will restrict the increase of the economic aggregate in Hubei.

The real economic growth is a main factor affecting the financial education investment of Hubei. The financial education investment is highly relying on the increase of the economic aggregate, and the economy growth and its development level determine the scale of the investment on education.

The economic increase elasticity of Hubei education investment is 0.899245 , that is to say when the education investment increased by $1 \%$, the GDP increased by $0.899245 \%$

From the pulse response analysis there is lag phase between the economic growth and financial education investment, while from the long-run, it exerts positive effect on the economic growth. And economic growth also contributes to the investment on education, which is not obvious. But from the long-term, it will benefit the financial education investment.

Generally speaking, education and economy promote, restrict each other and develop in harmonious way. Any unreasonable factor in any links will cause the disharmony of the whole development. The government should sort out the interaction mechanism and formulate more effective policies.

The result of the quantitative analysis on the financial education investment and the economic growth reveals that it is feasible and effective to realize the rapid development of the economic aggregate through increasing the education investment in Hubei Province. To focus on the importance of the education investment for the economic growth and to form a virtuous circle that there is a mutual promotion between economic growth and education investment is playing a strategic role in Hubei Province even nationwide.

\section{Acknowledgements}

Supported by Key Research Center for Humanities and Social Sciences in Hubei Province (Hubei University of Medicine)

\section{References}

[1] Wenlin FU,Kunrong Shen.China size and structure of public expenditure and the growth effects[J].Hubei:Economic Science.2006(1).

[2] Danhui Yi. Data analysis and application of Eviews[M]. Hubei: China Statistics Press, 2002:166-185.

[3] Lin Yifu Zhang Qi Liu Mingxing;Financial Structure and Economic Growth: The Case of Manufacturing Industry[J];World Economy;2003-01

[4] HE Guo-hua; A Study on the Relationship between Financial Structure and Firm Independent Innovation in China[J]. Economic Management Journal, 2011-03

[5] LI Xi-hui (Central University for Nationalities,Beijing,100081,China);On the Theory of Decision-making Power Creation System[J];Economic Management;2007-19 